\title{
RESEARCH
}

\section{Differences in admission rates and outcomes between men and women presenting to emergency departments with coronary syndromes}

\author{
Padma Kaul PhD, Wei-Ching Chang PhD, Cynthia M. Westerhout MSc, Michelle M. Graham MD, \\ Paul W. Armstrong MD
}

\section{ABSTRACT}

Background: Previous studies examining sex-related differences in the treatment of coronary artery disease have focused on patients in hospital. We sought to examine sexrelated differences at an earlier point in care - presentation to the emergency department.

Methods: We collected data on ambulatory care and hospital admissions for 54134 patients (44\% women) who presented to an emergency department in Alberta between July 1998 and March 2001 because of acute myocardial infarction, unstable angina, stable angina or chest pain. We used logistic regression and Cox regression analyses to determine sexspecific associations between the likelihood of discharge from the emergency department or coronary revascularization within 1 year and 1-year mortality after adjusting for age, comorbidities and socioeconomic factors.

Results: Following the emergency department visit, $91.3 \%$ of patients with acute myocardial infarction, $87.4 \%$ of those with unstable angina, $40.7 \%$ of those with stable angina and $19.8 \%$ of those with chest pain were admitted to hospital. Women were more likely than men to be discharged from the emergency department: adjusted odds ratio (and $95 \%$ confidence interval [CI]) 2.25 (1.75-2.90) for acute myocardial infarction, 1.71 (1.452.01) for unstable angina, $1.33(\mathbf{1 . 1 5 - 1 . 5 3 )}$ for stable angina and $1.46\left(1.3^{6}-1.57\right)$ for chest pain. Women were less likely than men to undergo coronary revascularization within 1 year: adjusted odds ratio (and 95\% Cl) $0.65(0.57-0.73)$ for myocardial infarction, $0.39(0.35-0.44)$ for unstable angina, $0.35(0.29-0.42)$ for stable angina and $0.32(0.27-0.37)$ for chest pain. Female sex had no impact on 1-year mortality among patients with acute myocardial infarction; it was associated with a decreased 1-year mortality among patients with unstable angina, stable angina and chest pain: adjusted hazard ratio (and 95\% Cl) o.6o (0.46$0.78), 0.60(0.46-0.78)$ and $0.74(0.63-0.87)$ respectively.

Interpretation: Women presenting to the emergency department with coronary syndromes are less likely than men to be admitted to an acute care hospital and to receive coronary revascularization procedures. These differences do not translate into worse outcomes for women in terms of 1-year mortality.

Une version française de ce résumé est disponible à l'adresse Www.cmaj.ca/cgi/content/full/I77/Io/II93/DCI

CMAJ 2007;177(10):1193-9
$\mathrm{F}$ or patients experiencing a new-onset acute cardiac event, the emergency department is usually the point of first contact with the health care system. A fraction of patients presenting to the emergency department are admitted to an acute care hospital for treatment or continued observation. Given that decisions made in the emergency department govern not only immediate but also longer-term treatment and outcomes, it is imperative that these decisions be appropriate.

The issue of gender bias in the treatment and outcomes of coronary artery disease has been examined extensively. The current guidelines of the American College of Cardiology and American Heart Association state that the treatment of acute coronary syndromes in women should be no different from that in men. ${ }^{1,2}$ However, several studies have found evidence to the contrary. There is general consensus that the frequency of cardiac catheterization is lower among women and that they undergo fewer revascularization procedures. ${ }^{3-11}$ Whether these lower rates are due to an inherent gender bias or indicate appropriate care continues to be debated.

Most studies of gender bias in cardiovascular care have focused either on patients in an acute care facility or on selected patient populations, such as those who have undergone cardiac catheterization. The few studies that have examined sexspecific differences in treatment decisions earlier in the process of care (i.e., in the emergency department) have either been single-centre studies ${ }^{12}$ or have involved clinical trial patients. ${ }^{13}$ Moreover, examination of sex-specific differences in cardiac care has traditionally been limited to more acute conditions, such as acute myocardial infarction and unstable angina. ${ }^{5,10,11,14-21}$ There is a need to expand our evaluation to a wider spectrum of coronary syndromes. We undertook the current study (a) to examine differences in rates of admission to acute care hospitals between men and women presenting to the emergency department with a main ambulatory care diagnosis of acute myocardial infarction, unstable angina, stable angina or chest pain and (b) to determine whether a patient's sex is an independent predictor of I-year treatment and outcomes in this cohort of patients.

From the Division of Cardiology (Kaul, Graham, Armstrong), Department of Medicine, and the Canadian VIGOUR Centre (Kaul, Chang, Westerhout, Armstrong), University of Alberta, Edmonton, Alta. 


\section{Methods}

\section{Data source}

Data for the study were retrieved from databases described previously and maintained by Alberta Health and Wellness. ${ }^{6}$ The Ambulatory Care Classification System database (which includes all visits to the ror emergency departments in the province, including patients brought by ambulance who died before arriving at the hospital) was used to identify the study cohort. Data from the Ambulatory Care Classification System database were merged with data from a hospital discharge database to identify subsequent admissions to hospital. Oneyear mortality rates were obtained from the Alberta Health Care Insurance Plan Registry. The provincial databases are comprehensive and can be linked by a unique patient identifier. Aggregate socioeconomic data for each of the I37 postal code areas were obtained from Statistics Canada's neighbourhood (area-wide) census data.

\section{Patient population}

We included in the study population all patients who presented to an emergency department of an acute care facility in Alberta between July I, 1998, and Mar. 3I, 200I, with a main ambulatory care diagnosis of acute myocardial infarction, unstable angina, stable angina or chest pain, as defined by the International Classification of Diseases, gth revision, Clinical Modification (for a list of the diagnostic codes, see Appendix I, available online at www.cmaj.ca/cgi/content/full/I77 /Io/II93/DC2). The main ambulatory care diagnosis refers to the main reason for provision of ambulatory care services to the service recipient. In the case of multiple diagnoses, the main ambulatory care diagnosis is the diagnosis responsible for that greatest use of resources.

A patient's index visit was his or her first emergency department visit during the study period that was because of a condition relating to any of the diagnoses of interest. To ensure that the index visit corresponded to a new episode, we excluded patients who were seen at an emergency department in the 3 months before the index visit and those who had been admitted to an acute care hospital because of a condition relating to a diagnoses of interest in the year before the index visit. To establish a complete patient risk profile, we considered a comorbidity to be present if it was reported during the index emergency department visit, during inpatient admission (if this occurred) concurrent to the emergency department visit or during any physician visit in the year before the index emergency department visit. The patient's initial diagnosis was determined from the record of the emergency department visit.

\section{Main outcomes}

The main outcomes included the number and proportion of patients admitted to an acute care facility within 48 hours after presenting with a new episode of acute myocardial infarction, unstable angina, stable angina or chest pain. The 48 hour window was used to ensure that interhospital transfers would be counted as admissions. In addition, we determined the proportion of patients undergoing revascularization (per- cutaneous coronary intervention or coronary artery bypass graft surgery) and the I-year mortality rates.

\section{Statistical analysis}

Means and standard deviations as well as median and interquartile ranges are presented for continuous variables. Values were compared across groups using Student's $t$ test and the nonparametric Mann-Whitney $U$ rank sum test, respectively. Categorical variables are presented as percentages, and comparisons were made using the $\chi^{2}$ test.

Multivariable logistic regression analysis was used to examine whether a patient's sex affected the likelihood of being discharged from the emergency department. The regression model included patient age as a continuous variable, sex (female v. male), residence in a metropolitan area (Edmonton or Calgary) and quartile of median household income at the neighbourhood level. To assess the impact of the presence of comorbidities on the likelihood of being discharged from the emergency department, we included a dichotomous riskfactor variable in the model, indicating whether the patient had diabetes, hypertension, congestive heart failure, cancer, cerebrovascular disease, renal disease, cardiac dysrhythmias or peripheral vascular disease.

To confirm the independent effect of a patient's sex on discharge status, we conducted a propensity-matched analysis to examine the robustness of the results of our multivariable analyses. We developed a logistic regression model to measure the propensity for early discharge. All baseline characteristics, excluding patient sex, were included in the model. The c-index for the model was 0.9I. We used the propensity score generated by this model to create a I-to-I matched cohort of patients who were admitted or discharged from the emergency department. A total of 6355 matched pairs were generated: 3476 patients were matched at the 5 -decimal level of the propensity score, 2137 at the 4 -decimal level, 694 at the 3 -decimal level and 48 at the 2-decimal level. We compared baseline characteristics of patients admitted and discharged from the emergency department in this propensity-matched cohort using Student's $t$ test, the nonparametric MannWhitney $U$ rank sum test and the $\chi^{2}$ test. Logistic regression analysis was used to assess the association between patient sex and emergency department discharge status in this matched cohort.

After adjusting for other baseline characteristics, we used multivariable logistic regression analysis to examine whether a patient's sex was independently associated with the likelihood of receiving coronary revascularization in the year following the index emergency department visit.

We used Kaplan-Meier analysis to generate I-year survival curves, and log-rank statistics to examine sex-specific differences in unadjusted survival rates among patients who were admitted to hospital and among those discharged from the emergency department. We used Cox regression analysis, with revascularization as a time-dependent covariate, to examine sex-specific differences in I-year mortality after adjusting for baseline variables.

The study was reviewed and approved by the ethics board of the University of Alberta. 


\section{Results}

During the 32-month study period, 54 I34 patients (44.2\% women) presented to the Ior emergency departments in $\mathrm{Al}-$ berta with a new episode of acute myocardial infarction, unstable angina, stable angina or chest pain. Of these, $63.1 \%$ ( $n=34 \mathrm{I} 45 ; 47.8 \%$ women) had chest pain, $\mathrm{I} 3.7 \%$ ( $n=74 \mathrm{IO}$; $39.3 \%$ women) had unstable angina, II. $6 \%(n=6290 ; 44.8 \%$ women) had stable angina, and Ir.6\% ( $n=6289 ; 29.7 \%$ women) had acute myocardial infarction.

Women were significantly older than men at presentation across all diagnoses (Table I). Comorbid conditions, such as hypertension and peripheral vascular disease, were higher among women than among men. Women were also more likely than men to be residents of metropolitan areas and to have lower median household income levels.

Overall, $3.5 \%$ of the patients presenting with acute myocardial infarction died in the emergency department; there was no significant sex-specific difference $(3.4 \%$ of men and $3.8 \%$ of women, $p=0.46$ ). One patient with unstable angina, 2 patients with stable angina and I patient with chest pain died in the emergency department. Among patients presenting with acute myocardial infarction, 91.3\% were admitted to an acute care hospital within 48 hours after the emergency department presentation. Similarly, $87.4 \%$ of the patients presenting with unstable angina, $40.7 \%$ of those with stable angina and $19.8 \%$ of those with chest pain were admitted to hospital. For all 4 diagnoses of interest, women were significantly less likely than men to be admitted to hospital ( $p<0.0 \mathrm{r}): 89.4 \%$ of women $\mathrm{v}$. $92.1 \%$ of men with acute myocardial infarction; $84.9 \%$ of women v. $88.9 \%$ of men with unstable angina; $38.5 \%$ of women v. $42.5 \%$ of men with stable angina; and I $8.1 \%$ of women V. $2 \mathrm{I} .3 \%$ of men with chest pain (Figure I).

About $60 \%$ of the patients with acute myocardial infarction, $53.8 \%$ of those with unstable angina, $22.6 \%$ of those with stable angina and $8.2 \%$ of patients with chest pain had at least I risk factor at baseline. Women were significantly more likely than men to have at least I risk factor among the patients with acute myocardial infarction $(66.4 \%$ v. $55.4 \%$ respectively, $p<0.0$ I) and among those with unstable angina ( $56.9 \%$ v. $5 \mathrm{I} .8 \%$ respectively, $p<0.0 \mathrm{I}$ ). There were no such sex-specific difference among those with stable angina or chest pain. The presence of a risk factor was associated with dramatically reduced odds of discharge from the emergency department (see Appendix 2, available online at www.cmaj.ca /cgi/content/full/177/Io/II93/DC2). Also, patients residing in

Table 1: Baseline characteristics of men and women presenting to emergency departments in Alberta between July 1, 1998, and Mar. 31, 2001, because of a new episode of acute myocardial infarction, unstable angina, stable angina or chest pain*

\begin{tabular}{|c|c|c|c|c|c|c|c|c|c|c|c|c|}
\hline \multirow[b]{2}{*}{ Characteristic } & \multicolumn{3}{|c|}{ Acute myocardial infarction } & \multicolumn{3}{|c|}{ Unstable angina } & \multicolumn{3}{|c|}{ Stable angina } & \multicolumn{3}{|c|}{ Chest pain } \\
\hline & $\begin{array}{c}\text { Men } \\
n=4419\end{array}$ & $\begin{array}{l}\text { Women } \\
n=1870\end{array}$ & $p$ value & $\begin{array}{c}\text { Men } \\
n=4500\end{array}$ & $\begin{array}{l}\text { Women } \\
n=2910\end{array}$ & $p$ value & $\begin{array}{c}\text { Men } \\
n=3475\end{array}$ & $\begin{array}{l}\text { Women } \\
n=2815\end{array}$ & $p$ value & $\begin{array}{c}\text { Men } \\
n=17837\end{array}$ & $\begin{array}{c}\text { Women } \\
n=16308\end{array}$ & $p$ value \\
\hline \multicolumn{13}{|l|}{ Age, yr } \\
\hline Mean (SD) & $62(13)$ & $70(13)$ & $<0.01$ & $62(13)$ & $67(13)$ & $<0.01$ & $61(14)$ & $67(14)$ & $<0.01$ & $49(17)$ & $52(18)$ & $<0.01$ \\
\hline Median & 61.5 & 71.4 & $<0.01$ & 62.5 & 67.7 & $<0.01$ & 61.9 & 68.8 & $<0.01$ & 47.0 & 50.6 & $<0.01$ \\
\hline Hypertension & 23.1 & 34.7 & $<0.01$ & 28.7 & 36.1 & $<0.01$ & 12.2 & 13.9 & 0.05 & 3.9 & 5.0 & $<0.01$ \\
\hline $\begin{array}{l}\text { Congestive heart } \\
\text { failure }\end{array}$ & 14.5 & 19.4 & $<0.01$ & 6.6 & 7.0 & 0.42 & 2.6 & 3.4 & 0.09 & 0.7 & 0.8 & 0.57 \\
\hline Cancer & 3.8 & 4.4 & 0.23 & 3.9 & 2.9 & 0.02 & 1.8 & 1.6 & 0.50 & 0.8 & 0.7 & 0.28 \\
\hline $\begin{array}{l}\text { Cerebrovascular } \\
\text { disease }\end{array}$ & 7.0 & 6.6 & 0.55 & 7.3 & 5.6 & $<0.01$ & 2.9 & 2.3 & 0.18 & 1.2 & 0.9 & 0.02 \\
\hline $\begin{array}{l}\text { Peripheral } \\
\text { vascular disease }\end{array}$ & 5.4 & 7.3 & $<0.01$ & 6.4 & 7.8 & 0.02 & 2.8 & 3.5 & 0.13 & 1.1 & 1.4 & 0.02 \\
\hline Metro resident $†$ & 49.8 & 51.7 & 0.18 & 58.3 & 62.1 & $<0.01$ & 43.0 & 44.8 & 0.16 & 40.4 & 42.5 & $<0.01$ \\
\hline $\begin{array}{l}\text { Median household } \\
\text { income, } \neq \$\end{array}$ & 54780 & 50894 & $<0.01$ & 56157 & 54249 & $<0.01$ & 53531 & 50470 & $<0.01$ & 53746 & 52800 & $<0.01$ \\
\hline Income quartile & & & $<0.01$ & & & $<0.01$ & & & $<0.01$ & & & $<0.01$ \\
\hline$\leq \$ 39191$ & 23.1 & 30.3 & & 21.0 & 24.7 & & 25.0 & 30.0 & & 24.2 & 26.1 & \\
\hline$\$ 39192-\$ 49975$ & 25.1 & 26.8 & & 23.8 & 24.3 & & 24.5 & 26.5 & & 25.2 & 25.9 & \\
\hline$\$ 49976-\$ 63581$ & 24.7 & 21.9 & & 26.0 & 25.0 & & 25.8 & 23.0 & & 25.2 & 24.1 & \\
\hline$\geq \$ 63582$ & 27.1 & 21.0 & & 29.2 & 26.0 & & 24.7 & 20.5 & & 25.4 & 23.9 & \\
\hline
\end{tabular}

Note: $\mathrm{SD}=$ standard deviation, $\mathrm{SES}=$ socioeconomic status.

*Values shown are percentages of patients unless stated otherwise.

†Patient lives in Edmonton or Calgary.

$\ddagger$ At the neighbourhood level. 
metropolitan areas (Calgary or Edmonton) were more likely than patients living elsewhere in Alberta to be discharged from the emergency department.

The results of the multivariable logistic analysis were confirmed by the propensity-matched analysis of a subset of 6355 patients. A score for propensity of discharge from the emergency department was based on the patients' baseline characteristics, excluding sex. In this matched cohort, $38.7 \%$ of the patients admitted to hospital and $48.0 \%$ of patients discharged from the emergency department were female $(p<0.01)$. There were no other significant baseline differences between the 2 groups (see Appendix $3 \mathrm{~A}$, available at www.cmaj.ca/cgi/content /full/177/Io/I193/DC2). Female sex was associated with higher odds of discharge from the emergency department before and after adjusting for other factors (see Appendix $3 \mathrm{~B}$, available online at www.cmaj.ca/cgi/content/full/177/Io/II93/DC2).

For all 4 diagnoses of interest, female sex was associated with a decreased likelihood of coronary revascularization within I year after the index emergency department visit, even after we adjusted for differences in baseline characteristics (Figure 2).
Diagnosis

Acute myocardial infarction

Unstable angina

Stable angina

Chest pain

Acute myocardial infarction

Unstable angina

Stable angina

Chest pain
Unadjusted OR $(95 \% \mathrm{Cl})$

$1.53(1.22-1.92)$

$1.43(1.24-1.64)$

$1.18(1.07-1.31)$

$1.22(1.16-1.29)$

Adjusted OR $(95 \% \mathrm{Cl})$

$2.25(1.75-2.90)$

$1.71(1.45-2.01)$

$1.33(1.15-1.53)$

$1.46(1.36-1.57)$

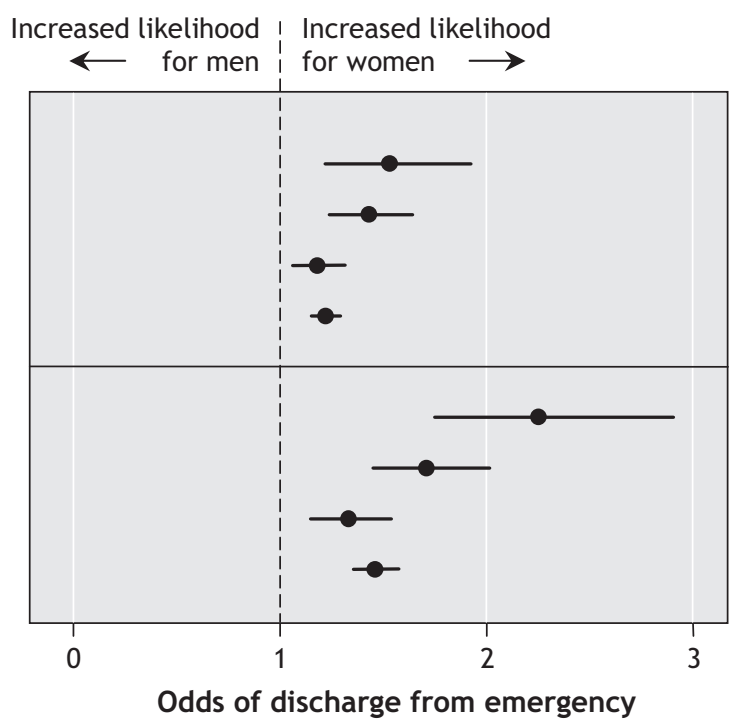

Figure 1: Odds of women ( $n=23903$ ) versus men ( $n=30$ 231) being discharged from the emergency department, by diagnosis. $\mathrm{OR}=$ odds ratio, $\mathrm{Cl}=$ confidence interval.

Diagnosis

Acute myocardial infarction

Unstable angina

Stable angina

Chest pain

Acute myocardial infarction

Unstable angina

Stable angina

Chest pain
Unadjusted OR $(95 \% \mathrm{Cl})$

$0.58(0.51-0.65)$

0.41 (0.37-0.46)

$0.37(0.31-0.44)$

$0.37(0.32-0.43)$

Adjusted OR (95\% Cl)

$0.65(0.57-0.73)$

$0.39(0.35-0.44)$

$0.35(0.29-0.42)$

$0.32(0.27-0.37)$

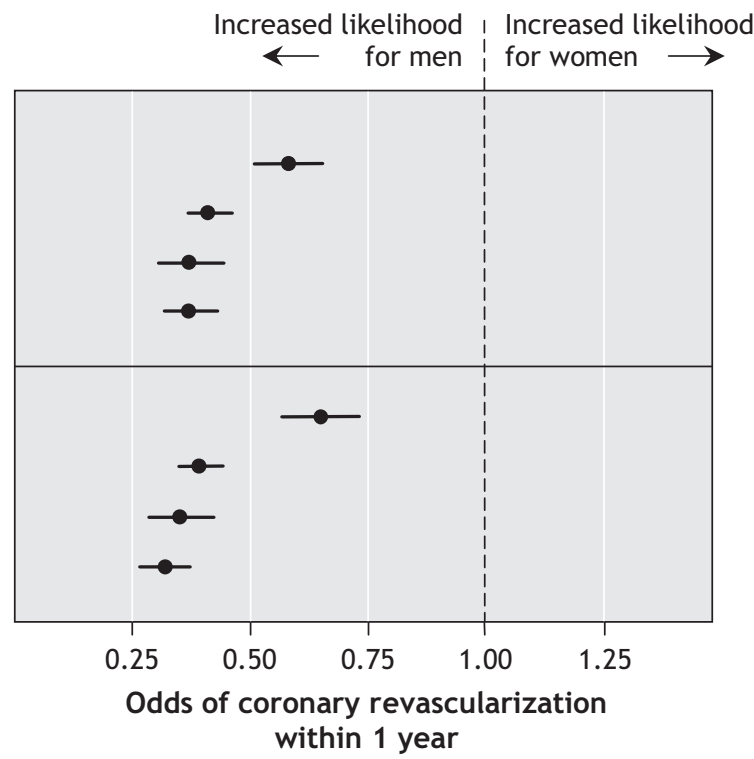

Figure 2: Odds of women ( $n=23$ 903) versus men ( $n=30$ 231) undergoing coronary revascularization within 1 year after index emergency department visit, by diagnosis. $\mathrm{OR}=$ odds ratio, $\mathrm{Cl}=$ confidence interval. 
Among the patients who were admitted to hospital, rates of revascularization were higher among men than among women across all diagnoses (see Appendix 4, available online at www .cmaj.ca/cgi/content/full/I77/Io/II93/DC2). However, men were significantly more likely than women to visit the emergency department within I year with a repeat myocardial infarction. There were no sex-specific differences in the number of days to repeat myocardial infarction, except among patients who presented with stable angina. Among patients with unstable angina, stable angina and chest pain who were discharged from the emergency department, rates of revascularization were higher among men than among women (see Appendix 5, available online at www.cmaj.ca/cgi/content/full/177/Io/I193/DC2). Except for patients with chest pain, there were no significant differences between men and women in terms of readmission rates and additional emergency department visits.

The only significant difference between men and women in I-year mortality was observed among patients with acute myocardial infarction (Figure 3). However, in a Cox regression model in which we adjusted for baseline characteristics and treated coronary revascularization as a time-dependent covariate, female sex had no impact on I-year mortality among patients with acute myocardial infarction and was associated with a decreased I-year mortality among patients with unstable angina, stable angina and chest pain (see Appendix 6, available online at www.cmaj.ca/cgi/content/full /I77/IO/II93/DC2). Other predictors of an increased risk of Iyear mortality across all diagnoses included cerebrovascular disease and renal disease.

\section{Interpretation}

In this study, women who presented to the emergency department with a new episode of acute myocardial infarction, un- stable angina, stable angina or chest pain were less likely than their male counterparts to be admitted to an acute care facility within 48 hours. Consistent with findings from previous studies, ${ }^{22,23}$ women in our study were older and more likely than men to have comorbidities, such as hypertension and peripheral vascular disease. Also, women were less likely than men to undergo coronary revascularization procedures during the year following their index emergency department visit. However, this seemingly less aggressive approach to treatment among the women had no impact on their I-year mortality. After adjusting for baseline characteristics, we found no sex-specific differences in I-year mortality among patients who presented with acute myocardial infarction; among patients with unstable angina, stable angina and chest pain, female sex was associated with a decreased I-year mortality. A possible explanation for this finding is the higher prevalence of normal coronary arteries among women presenting with angina symptoms than among men, as documented by previous studies. ${ }^{24,25}$

Our examination of an earlier point in the care spectrum revealed that $3.5 \%$ of patients presenting with acute myocardial infarction died in the emergency department. Although there was no significant sex-specific difference in mortality, this information has not been accounted for in studies that only included patients admitted to inpatient facilities or who have undergone cardiac catheterization.

We also found that $5.2 \%$ of the patients with acute myocardial infarction, $\mathrm{I} 2.6 \%$ of those with unstable angina, $59.3 \%$ of those with stable angina and $80.2 \%$ of the patients with chest pain were discharged alive from the emergency department. Consistent with the few studies that examined patients presenting to the emergency department, ${ }^{10,12,13}$ we found that women were less likely than men to be admitted to hospital. After adjusting adjusted for differences in pre-

$\begin{array}{lc}\text { Diagnosis } & \begin{array}{c}\text { Unadjusted hazard } \\ \text { ratio }(95 \% \mathrm{Cl})\end{array} \\ \text { Acute myocardial infarction } & 1.72(1.48-2.02) \\ \text { Unstable angina } & 0.79(0.62-1.01) \\ \text { Stable angina } & 0.96(0.74-1.23) \\ \text { Chest pain } & 0.89(0.77-1.04) \\ & \begin{array}{c}\text { Adjusted hazard } \\ \text { ratio }(95 \% \mathrm{Cl})\end{array} \\ \text { Acute myocardial infarction } & 1.10(0.91-1.35) \\ \text { Unstable angina } & 0.60(0.46-0.78) \\ \text { Stable angina } & 0.60(0.46-0.78) \\ \text { Chest pain } & 0.74(0.63-0.87)\end{array}$

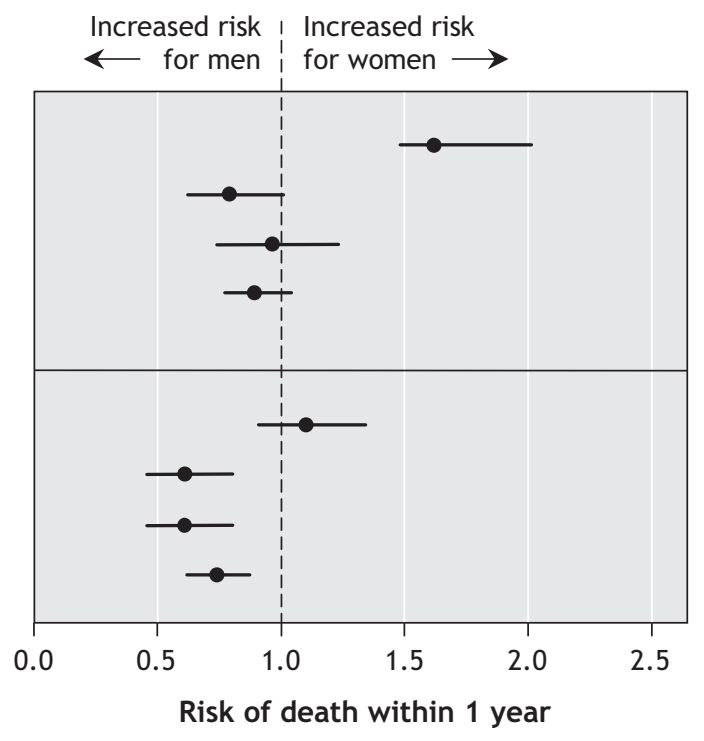

Figure 3: Risk of women ( $n=23903)$ versus men $(n=30231)$ dying within 1 year after index emergency department visit, by diagnosis. $\mathrm{Cl}$ = confidence interval. 
senting characteristics, we found that female sex was significantly associated with an increased likelihood of discharge from the emergency department across all 4 diagnoses. These results were confirmed in the propensity-matched analysis. Residence in a metropolitan area was also associated with an increased likelihood of discharge among patients with unstable angina, stable angina and chest pain, which suggested that easy access to acute care facilities may play a role in the decision to discharge patients from the emergency department.

The reasons why patients with acute myocardial infarction and unstable angina were discharged from the emergency department requires further investigation, especially given the findings from our study and previous studies that showed that patients with acute myocardial infarction who were discharged had worse outcomes than those who were admitted to hospital. ${ }^{12,13}$ Possible explanations for discharge include the presence of normal electrocardiograms or electrocardiograms confounded by other abnormalities, such as left ventricular hypertrophy or left bundle-branch block. Women are more likely than men to present with nondiagnostic electrocardiograms and atypical symptoms, ${ }^{15,25,26}$ which may explain their higher rate of discharge. Unfortunately, the administrative databases used in our study do not contain information on the electrocardiograms or on other detailed clinical or laboratory information that would allow us to determine the extent to which these factors may have contributed to the discharge of patients from the emergency department. Prospectively designed cohort studies capturing more detailed data, especially at hospitals with established chest-pain units, may be able to provide better insight into effective triage of this population in the emergency department.

Some limitations of our study should be noted. There were significant differences in the baseline characteristics of the men and women included in our study. Although we used statistical methods to adjust for these differences, residual confounding may have remained as a result of both observed and unobserved differences between the sexes that may explain the difference in outcomes. Our study did not contain the level of detail of clinical or laboratory tests captured in registries or clinical trials. Previous assessments have found the coding of diagnoses by medical records personnel of patients admitted to hospital to be both accurate and complete. However, no formal assessment of the accuracy of the coding of the ambulatory care data has been conducted. Although evidence suggests that it is valid, ${ }^{27}$ our use of median household income at the neighbourhood level may not always accurately reflect an individual patient's socioeconomic status.

Our decision to include patients presenting with chest pain requires clarification. Chest pain is a symptom that may or may not be related to cardiovascular disease. However, we believe that it was important to include it, because many patients with cardiovascular disease present with chest pain. With respect to the primary outcomes of our study - the relation between the sex of a patient and admission status and outcomes - the results observed for the patients with chest pain were similar to those for the patients with the other 3 cardiovascular diagnoses.

\section{Conclusions}

Among patients presenting to an emergency department with a main ambulatory care diagnosis of acute myocardial infarction, unstable angina, stable angina or chest pain, we found that women were more likely than men to be discharged home and less likely than men to undergo cardiac catheterization or revascularization in the year following their index visit to the emergency department. However, this more conservative approach to treatment among women did not appear to have an impact on the I-year mortality in this patient population.

\section{This article has been peer reviewed.}

Competing interests: None declared.

Contributors: Padma Kaul contributed to the conception and design of the study and the acquisition, analysis and interpretation of the data and drafted the article. Wei-Ching Chang, Cynthia Westerhout and Michelle Graham contributed to the acquisition of data and revised the article critically for important intellectual content. Paul Armstrong contributed to the conception and design of the study and the acquisition of data and revised the article critically for important intellectual content. All of the authors gave final approval of the version to be published.

Acknowledgements: Funding for the study was provided by an operating grant from the Canadian Institutes of Health Research (CIHR). Padma Kaul is supported by CIHR and the Alberta Heritage Foundation for Medical Research.

Padma Kaul has had full access to all of the data in the study and takes responsibility for the integrity of the data and the accuracy of the data analysis. Although the study is based in part on data provided by Alberta Health and Wellness, the interpretation and conclusions contained herein are those of the authors and do not necessarily represent the views of the Government of Alberta. Neither the Government of Alberta nor Alberta Health and Wellness express any opinion in relation to this study.

\section{REFERENCES}

I. Antman EM, Anbe DT, Armstrong PW, et al. ACC/AHA guidelines for the management of patients with ST-elevation myocardial infarction - executive summary: a report of the American College of Cardiology/American Heart Association Task Force on Practice Guidelines (Writing Committee to Revise the 1999 Guidelines for the Management of Patients with Acute Myocardial Infarction). Circulation 2004; IIO: $588-636$.

2. Braunwald E, Antman EM, Beasley JW, et al. ACC/AHA guidelines for the management of patients with unstable angina and non-ST-segment elevation myocardial infarction: executive summary and recommendations. A report of the American College of Cardiology/American Heart Association Task Force on Practice Guidelines (Committee on the Management of Patients with Unstable Angina). Circulation 2000;102:1193-209.

3. Pepine CJ. Ischemic heart disease in women: facts and wishful thinking. J Am Coll Cardiol 2004;43:1727-30

4. Bairey Merz N, Bonow RO, Sopko G, et al. Women's Ischemic Syndrome Evaluation: current status and future research directions: report of the National Heart, Lung and Blood Institute workshop, October 2-4, 2002: executive summary. Circulation 2004;109:805-7.

5. Blomkalns AL, Chen AY, Hochman JS, et al. Gender disparities in the diagnosis and treatment of non-ST-segment elevation acute coronary syndromes: large-scale observations from the CRUSADE (Can Rapid Risk Stratification of Unstable Angina Patients Suppress Adverse Outcomes With Early Implementation of the American College of Cardiology/American Heart Association Guidelines). J Am Coll Cardiol 2005;45:832-7.

6. Rathore SS, Chen J, Wang Y, et al. Sex differences in cardiac catheterization: the role of physician gender. JAMA 2001;286:2849-56.

7. Ghali WA, Faris PD, Galbraith PD, et al. Sex differences in access to coronary revascularization after cardiac catheterization: importance of detailed clinical data. Ann Intern Med 2002;136:723-32.

8. Chang WC, Kaul P, Westerhout CM, et al. Impact of sex on long-term mortality from acute myocardial infarction vs unstable angina. Arch Intern Med 2003;163:2476-84.

9. Schulman KA, Berlin JA, Harless W, et al. The effect of race and sex on physicians' recommendations for cardiac catheterization. N Engl J Med I999;340:618-26.

Io. Roger VL, Farkouh ME, Weston SA, et al. Sex differences in evaluation and outcome of unstable angina. JAMA 2000;283:646-52. 
II. Chandra NC, Ziegelstein RC, Rogers WJ, et al. Observations of the treatment of women in the United States with myocardial infarction. a report from the National Registry of Myocardial Infarction-I. Arch Intern Med I998;158:98I-8.

12. Herlitz J, Karlson BW, Lindqvist J, et al. Characteristics and long-term outcome of patients with acute chest pain or other symptoms raising suspicion of acute myocardial infarction in relation to whether they were hospitalized or directly discharged from the emergency department. Coron Artery Dis 2002;13:37-43.

I3. Pope JH, Aufderheide TP, Ruthazer R, et al. Missed diagnosis of acute cardiac ischemia in the emergency department. NEngl J Med 2000;342:1163-70.

I4. Alter DA, Naylor CD, Austin PC, et al. Biology or bias: practice patterns and long term outcomes for men and women with acute myocardial infarction. J Am Coll Cardiol 2002;39:1909-I6.

I5. Goldberg RJ, O'Donnell C, Yarzebski J, et al. Sex differences in symptom presentation associated with acute myocardial infarction: a population-based perspective. Am Heart J I998; 136:189-95.

I6. Gottlieb S, Harpaz D, Shotan A, et al. Sex differences in management and outcome after acute myocardial infarction in the I99os: a prospective observational community-based study. Circulation 2000;102:2484-90.

I7. Hochman JS, McCabe CH, Stone PH, et al. Outcome and profile of women and men presenting with acute coronary syndromes: a report from TIMI IIIB. J Am Coll Cardiol I997;30:I4I-8.

I8. Kim C, Schaaf $\mathrm{CH}$, Maynard C, et al. Unstable angina in the myocardial infarction triage and intervention registry (MITI): short- and long-term outcomes in men and women. Am Heart J 200I; I4I:73-7.

I9. Rathore SS, Berger AK, Weinfurt KP, et al. Race, sex, poverty, and the medical treatment of acute myocardial infarction in the elderly. Circulation 2000;102:642-8.
20. Stone PH, Thompson B, Anderson HV, et al. Influence of race, sex, and age on management of unstable angina and non-Q-wave myocardial infarction: the TIMI III registry. JAMA I996;275:IIO4-I2.

2I. Vaccarino V, Krumholz HM, Yarzebski J, et al. Sex differences in 2-year mortality after hospital discharge for myocardial infarction. Ann Intern Med 200I;134:173-8I.

22. Clinical Quality Improvement Network (CQIN) Investigators. Low incidence of assessment and modification of risk factors in acute care patients at high risk for cardiovascular events, particularly among females and the elderly. Am J Cardiol I995; 76:570-3.

23. Gregor RD, Bata IR, Eastwood BJ, et al. Gender differences in the presentation, treatment, and short-term mortality of acute chest pain. Clin Invest Med I994;17:55I-62.

24. Merz NB, Johnson BD, Kelsley PSF, et al. Diagnostic, prognostic, and cost assessment of coronary artery disease in women. Am J Manag Care 2001;7:959-65.

25. Cerqueira MD. Diagnostic testing strategies for coronary artery disease: special issues related to gender. Am J Cardiol I995;75:52-6oD.

26. McSweeney JC, Cody M, O'Sullivan P, et al. Women's early warning symptoms of acute myocardial infarction. Circulation 2003;108:2619-23.

27. Alter DA, Naylor CD, Austin P, et al. Effects of socioeconomic status on access to invasive cardiac procedures and on mortality after acute myocardial infarction. $N$ Engl J Med 1999;341:1359-67.

Correspondence to: Dr. Padma Kaul, Department of Medicine, University of Alberta, 7226 Aberhart Centre - I, 11402 University Ave., Edmonton AB T6G 2J3; fax 780 407-8368; pkaul@ualberta.ca 